\title{
Influence of Different Types of Treatments on Amazonian Vegetable Fibers on the Performance of Mortars Based on Portland Cement, Metakaolin and Fly Ash
}

\author{
Régis Pamponet da Fonseca * (1), Janaíde Cavalcante Rocha ${ }^{b}$, Malik Cheriaf $^{b}$ (1) \\ ${ }^{a}$ Universidade Federal do Amazonas (UFAM), Departamento de Engenharia Civil, \\ 69067-005, Manaus, AM, Brasil. \\ ${ }^{b}$ Universidade Federal de Santa Catarina, Programa de Pós-Graduação em Engenharia Civil, \\ 88040-900, Florianópolis, SC, Brasil.
}

Received: June 29, 2021; Revised: November 19, 2021; Accepted: November 29, 2021

\begin{abstract}
This study aimed to evaluate the physical, chemical, and mechanical properties of different Amazonian vegetable fibers to produce cementitious mortars reinforced with different types of vegetable fibers from the Amazon. Also, to analyze the influence of different types of chemical and physical treatments, on the direct tensile strength of vegetable fibers, water absorption of vegetable fibers and on the mechanical properties of compressive strength, flexural strength, and water absorption of mortars. Four vegetable fibers from the Amazon rainforest, from the Upper Rio Negro region (piassava, jute, tucum and razor grass) were used to produce cement composites with 50\% Portland CPII-F cement and additions of supplementary cement materials ( $40 \%$ metakaolin and $10 \%$ fly ash), with cement mortar and sand trace 1:2:0.60. The cementitious composites were subjected to two types of curing: initial curing in air followed by final curing in water and curing in a pressurized autoclave with $\mathrm{CO}_{2}$, both for 28 days. The treatments applied to the fibers were: washing with hot water; hornification; chemical treatment with sodium hydroxide and hybridization (hot water washing coupling, hornification, sodium hydroxide $(\mathrm{NaOH})$ and application of hydrogen peroxide $\left(\mathrm{H}_{2} \mathrm{O}_{2}\right)$ ). As a result, the hybridization treatment increased the mechanical strength of the tucum fiber from $67.20 \mathrm{MPa}$ (untreated fiber) to $318.80 \mathrm{MPa}$ (treated), corroborating the increase in the crystallinity index from $59.84 \%$ to $66.73 \%$. The flexural strength of cementitious composites reinforced with $4.5 \%$ tucum fibers and razor grass submitted to curing in an autoclave with $\mathrm{CO}_{2}$ was, respectively, $49.61 \%$ and $61.75 \%$ higher than the reference composite (without fibers) in the water curing. Therefore, both the autoclave cure and the hybridization treatment proved to be viable for its application in composites with vegetable fibers.
\end{abstract}

Keywords: Water Absorption, Natural Fibers, Cement Composites, Autoclaved cure, Mechanical properties.

\section{Introduction}

The search for new construction technologies in the construction industry that have such as impetus, economy, and speed of execution, are determining factors to produce sustainable building materials, and alternatives using renewable resources ${ }^{1}$.

Based on this premise, the raw material must be viable from an ecological point of view and waste disposal. The application of fibers in cementitious composites and materials for use in construction has been known for thousands of years. In the most remote times, the use of fibers to reinforce cementitious materials was carried out empirically.

Mineral and synthetic fibers are used all over the planet, but the first one such as (asbestos) causes health problems, and the synthetic ones, such as polyvinyl alcohol (PVA) and polypropylene for the manufacture it is necessary to use several chemical components which it is not the most suitable to produce eco sustainable and renewable materials ${ }^{2}$.

*e-mail: regispamponet@ufam.edu.br
Therefore, the use of vegetable fibers, with characteristics like, or superior to, mineral and synthetic fibers, becomes viable, to produce sustainable materials, once that come from a renewable source, biodegradable and have high availability, and its cost is considered relatively low. The use of vegetable fibers, with characteristics like or superior to mineral and synthetic fibers, becomes viable to produce sustainable materials and Brazil is one of the largest natural fiber producing countries in the world ${ }^{2,3}$.

To evaluate the mechanical properties and capillary water absorption of mortars with Amazon fibers, this research used fibers of the piassava species (Leopoldinia piassaba), the tucum palm (Astrocaryum chambira Burret) and the razor grass (Echinochloa polystachya) to produce cementitious composites, also due to the large amount of research on the physicochemical properties of jute fiber, this fiber was used in the present study for comparative purposes. Piassava, tucum palm and razor grass fibers have no studies on the influence of their physical and chemical properties within cementitious matrices.

Since the high moisture absorption is a great problem for natural fiber composites, especially in outdoor structures, 
natural fibers must be treated, specially by physical-chemical treatments ${ }^{4}$, because it can be deteriorated in the alkaline environment of cementitious composites. Also, we used supplementary cementitious materials SCMs (fly ash and metakaolin) to improve the susceptibility to portlandite. A $\mathrm{CO}_{2}$ curing procedure was used to contribute to densification of fibers cement materials, allied with the application four types of fiber treatments ${ }^{5,6}$.

The objective of this research was to evaluate the use of natural fibers, as an alternative to reinforce cement-based composite materials, through the proposal of alternative treatments applied to natural fibers. For the manufacture of mortars, supplementary cementing materials (SCMs) were incorporated as well as the use of curing in $\mathrm{CO}_{2}$ autoclave, both with the purpose of improving the mechanical properties and durability of fiber-cement composites.

The novelty of this research is the use of fibers from the Amazon that have never been used (such as tucum and razor grass) and simple treatments (such as the hybridization treatment) combined with the cure with autoclaved $\mathrm{CO}_{2}$ that can provide a densification of the matrix.

\section{Experimental}

\subsection{Materials}

The Natural fibers used in the study came from Amazon Forest. The cement Portland used CPII-F 40 according to Brazilian standard NBR $16697^{7}$, supplementary cementitious materials (fly ash and metakaolin). The fly ash came from pulverized coal mineral produced in thermoelectric plant installed at cellulose industry, it was dry sieved to obtain particles less than $75 \mu \mathrm{m}$. The HP ULTRA metakaolin was provided by the company Metakaolin of Brazil. Table 1 shows the chemical compositions and physical properties of cement, fly ash and metakaolin.

Natural fibers can be deteriorated in the alkaline environment of cementitious composites, we used supplementary cementitious materials SCMs (fly ash and metakaolin) to improve the susceptibility to portlandite and reduce the amount of calcium hydroxide of the samples.
Chemical composition was determined by energy dispersive X-ray fluorescence spectrometer EDX $7000 \mathrm{Hs}$ (Shimadzu, Tokyo, Japan), in terms of total oxide (wt.\%).

To produce the cement composites, a natural sand was used as a fine aggregate, the fineness, specific gravity, and natural moisture content of this sand were respectively $1.90 ; 2650 \mathrm{~kg} / \mathrm{m}^{3}$ and $7.90 \%$. A sodium polycarboxylate superplasticizer additive (SP) was used to improve the fluidity of fresh mixtures.

Natural fibers were sampled for chemical analysis following the Standards of (TAPPI) - Pulp and Paper Industry Technical Association. Therefore, Table 2 shows the fibers were chemically characterized to quantify cellulose; extractives; lignin and ash. Fibers with high cellulose content usually present superior tensile strength ${ }^{6-8}$.

Fiber measurement (morphological analysis) was performed using a Binocular Stereoscopic Microscope model Stemi 2000-C from Zeiss (Oberkochen, Germany).

The tucum palm fibers have lengths between $2.00 \mathrm{~m}$ and $8.00 \mathrm{~m}$ and $0.08 \mathrm{~mm}$ of thickness (does not have a circular shape), the razor grass fibers have lengths between $0.5 \mathrm{~m}$ and $0.75 \mathrm{~m}$ with $1.00 \mathrm{~mm}$ of diameter, both coming from the leaves of the plants. Jute fibers have a length of $1.00 \mathrm{~m}$ to $4.00 \mathrm{~m}$ with $1.08 \mathrm{~mm}$ of diameter, piassava fibers have lengths ranging from $0.60 \mathrm{~m}$ to $2.00 \mathrm{~m}$ with $0.8 \mathrm{~mm}$ of diameter, both coming from the stems of the plants.

The Young's modulus of tucum palm, razor grass, jute and piassava fibers were 4.03 GPa, $70 \mathrm{GPa}, 10 \mathrm{GPa}$ and $1.20 \mathrm{GPa}$; respectively. All nature fibers presented an Elongation at failure $(\%)$ of the $1.5 \%, 0.5 \%, 1.9 \%$ and $17.8 \%$; respectively to the tucum palm, razor grass, jute, and piassava fibers, The young's modulus of the fibers was determined using the universal machine Instron 5569 machine.

\subsection{Fibers Treatment}

Four treatments were applied in natural fibers: Fibers washed in hot water; Hornification; sodium hydroxide treatment and hybridization. After the treatment, all the fibers were cut $15 \mathrm{~mm}$ long. Natural fibers that have been rinsed in water and dried in a $60^{\circ} \mathrm{C}$ oven for 24 hours.

The treatment of washing in hot water was carried out according to Lertwattanaruk and Suntijitto ${ }^{3}$ and Tian et al. ${ }^{6}$, studies. The hornification treatment process consisted in

Table 1. Chemical and physical composition of cement, fly ash and metakaolin.

\begin{tabular}{cccccccccccc}
\hline Materials & L.O.I & $\mathrm{CaO}$ & $\mathrm{SiO}_{2}$ & $\mathrm{MgO}$ & $\mathrm{Al}_{2} \mathrm{O}_{3}$ & $\mathrm{SO}_{3}$ & $\mathrm{Fe}_{2} \mathrm{O}_{3}$ & $\mathrm{~K}_{2} \mathrm{O}$ & $\begin{array}{c}\mathrm{TiO}_{2} \\
\begin{array}{c}\text { Specific } \\
\text { Gravity } \\
\left(\mathrm{g} / \mathrm{cm}^{3}\right)\end{array}\end{array} \begin{array}{c}\text { Fineness } \\
\left(\mathrm{cm}^{2} / \mathrm{g}\right)\end{array}$ \\
\hline Cement (CPII-F 40) & 5.38 & 54.5 & 19.96 & 8.34 & 4.25 & 3.81 & 2.29 & 0.92 & 0.26 & 3.17 & 3605 \\
\hline Fly Ash (FA) & 0.80 & 2.31 & 61.18 & 0.70 & 30.64 & 0.36 & 1.67 & 1.27 & 0.81 & 2.17 & 3337 \\
\hline Metakaolin (MK) & 2.38 & 0.12 & 43.90 & - & 46.56 & 0.08 & 3.05 & 0.46 & 0.76 & 2.81 & 12531 \\
\hline
\end{tabular}

L.O.I: loss on ignition

Table 2. Chemical composition of untreated fibers.

\begin{tabular}{cccccc}
\hline Fiber & Holocellulose (\%) & Alpha-cellulose (\%) & Hemicellulose (\%) & Lignin (\%) & Extractives (\%) \\
\hline Piassava & 53.16 & 51.45 & 1.71 & 45.68 & 1.17 \\
\hline Tucum palm & 78.90 & 77.52 & 1.38 & 17.36 & 3.74 \\
\hline Razor grass & 95.3 & 86.85 & 8.45 & 0.81 & 3.89 \\
\hline Jute & 83.18 & 64.07 & 19.11 & 12.46 & 4.36 \\
\hline
\end{tabular}


the application of 10 wetting/drying cycles, with procedure analogous to Asasutjaritet et al..$^{9}$, and Ferreira et al. ${ }^{10}$, studies.

The $\mathrm{NaOH}$ treatment the fibers were placed in the sodium hydroxide solution $(2 \mathrm{~mol} / \mathrm{L})$, the ratio between fibers weight and used solution was 1:20, mixed homogeneously for 5 minutes and then rested for 1 hour. Neutralized with glacial acetic acid solution (1\%) for a 10 -minute period.

The hybridization process of treatment consisted of: Firstly, the fibers were washed in hot water; secondly hornification cycles process; then treatment with $\mathrm{NaOH}$ and finally a treatment with the application of $5 \%$ hydrogen peroxide solution for 3 hours, with 1:20 ratio fibers/solution.

\subsection{Fibers water absorption}

Fibers were cut $15 \mathrm{~mm}$ long with a scissors; dried at a temperature of $60 \pm 5^{\circ} \mathrm{C}$. Two grams of dry fiber $\left(\mathrm{W}_{\mathrm{df}}\right)$ were weighed and placed in a tea infusion ball, and covered with water for 24 hours, then the fibers were wrapped in absorbent paper (this condition was $\mathrm{W}_{\text {ssd }}=$ saturated and dry surface). Equation 1 shows the absorption of fibers by the water was calculated in percentage of mass (WA\%):

$$
W A \%=\left(W_{s s d}-W_{d f} / W_{d f}\right) \times 100
$$

\subsection{Crystallinity Index}

To measure the crystallinity index of the fibers before and after the treatments, the X-ray diffractometry (XRD) technique was used. The crystallinity index was determined according to the empirical method suggested by Segal et al. ${ }^{11}$. Crystallinity index (C.I) is calculated according to the following Equation 2:

$$
C . I=\left(I_{002}-I_{a m}\right) / I_{002}
$$

Where: $I_{002}$ corresponds to the maximum intensity of the diffraction peak, related to the crystalline part of the cellulose in plane (002) and $I_{a m}$ refers to the intensity of the background dispersion (amorphous part of the sample).

The fiber samples were cut by hand in a length of $1 \mathrm{~cm}$ and crushed in a knife mill (Wiley ${ }^{\circledR}$ Model 4 ) for 10 minutes. The fibers were then sieved in a 60 -mesh sieve $(0.25 \mathrm{~mm})$.

XDR analyses were performed using a desktop Rigaku Miniflex II (Tokyo, Japan) at an angular velocity of $0.02^{\circ}$

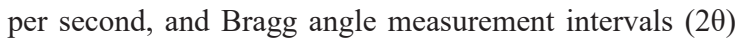
from $5^{\circ}$ to $60^{\circ}$, and the analyses were conducted with $(\mathrm{Cu}$ radiation) $\mathrm{k} \alpha=1.5418 \AA$.

\subsection{Fibers direct tensile strength}

The fiber direct tensile test was measured according to ASTM C $1557^{12}$ using a universal Instron 5569 machine. The test speed was $0.3 \mathrm{~mm} / \mathrm{min}$ with a load cell of $1 \mathrm{kN}$. The 12 fiber samples of each treatment were conditioned at room temperature $\left(23^{\circ} \mathrm{C}\right)$. The effective cross-sectional area was assumed to be circular.

\subsection{Mortar study}

The mix (50CPII-F+40MK+10FA) with $1.5 \%, 3.0 \%$ and $4.5 \%$ of fibers was used to mortar study and its performance compared to a reference mortar (CPII-F+MK+FA) without fibers. Mortars with mass ratio of 1:2 (binder to sand) and water to cement $\mathrm{w} / \mathrm{c}=0.6$ were cast into a prismatic mold with dimensions $40 \mathrm{~mm} \times 40 \mathrm{~mm} \times 160 \mathrm{~mm}$, according to NBR $13279^{13}$. After being demolded, the samples were cured until testing. The samples were prepared for submission to two series of cures: in water and in the $\mathrm{CO}_{2}$-autoclave. For each cure, the number of samples was $(\mathrm{N}=3)$. The fibers were previously saturated for 24 hours before molding, pouring the amount of water added to the mortar was corrected. After saturation, 3 additions of fibers were mixed to the mortar: $1.5 \%, 3.0 \%$ and $4.5 \%$. The mix were made using a planetary mixer. First the binder materials (CPII-F+MK+FA) were mixed for 1 minute at slow speed, then $80 \%$ of water and $80 \%$ of admixture were placed and mixture for another 1 minute at slow speed, after that, dry sand were mixed for another 1 minute at the same speed. Finally, were add the last $20 \%$ water and $20 \%$ admixtures, and randomly were placed the wet fibers, and mix for 3 minutes at medium speed.

\subsection{Cure Methods}

Two procedures for curing mortars were used: curing in water and curing in autoclave with $\mathrm{CO}_{2}$ inflation. The cure in the water consisted of leaving the composites for 28 days submerged in water at $23^{\circ} \mathrm{C}$, after 28 days they were dried in a heating chamber for 3 days at $50^{\circ} \mathrm{C}$ temperature.

The autoclaved cure consisted of placing the samples inside the autoclave, then filling with 22 liters of tap water. With a rubber hose, $\mathrm{CO}_{2}$ was inflated in the water for 7 minutes at a flow rate of $6 \mathrm{~L} / \mathrm{min}$, $\mathrm{pH}$ was verified through tapes (values between 5 and 6). The autoclave was then closed and switched on until the temperature was sufficient to generate a pressure of $0.05 \mathrm{MPa}$. After reaching this pressure, it was left on for 1 hour, each day during the 28 days of curing period.

\subsection{Mechanical tests and capillary water absorption of mortars}

Mechanical tests of strengths were performed in mortars (flexural and compressive test) both at 28 days, 3 prismatic samples of $40 \mathrm{~mm} \times 40 \mathrm{~mm} \times 160 \mathrm{~mm}$ were provided for the flexure test, six halves, resulting from the prisms splitted after the three flexure tests, were tested under compression with $40 \times 40 \mathrm{~mm}^{2}$ steel loading platens, according to the NBR $13279^{13}$ and capillary water absorption test were performed according to the NBR 9779 standard ${ }^{14}$.

\section{Results and Discussion}

\subsection{Fibers water absorption}

The graph in Figure 1 illustrates the water absorption of vegetable fibers with and without treatment. For piassava, tucum and razor grass fibers, hot water treatments and hornification presented the lowest water absorption, especially for the hornification treatment it was the treatment that presented the lowest water absorption. Chemical treatments ( $\mathrm{NaOH}$ solution and hybridization) resulted in greater water absorption.

This result confirms that the hornification treatment alters the surface of the fibrils grouping the cellulose polysaccharide chains, promoting less water absorption ${ }^{10,15,16}$ and the hot water 


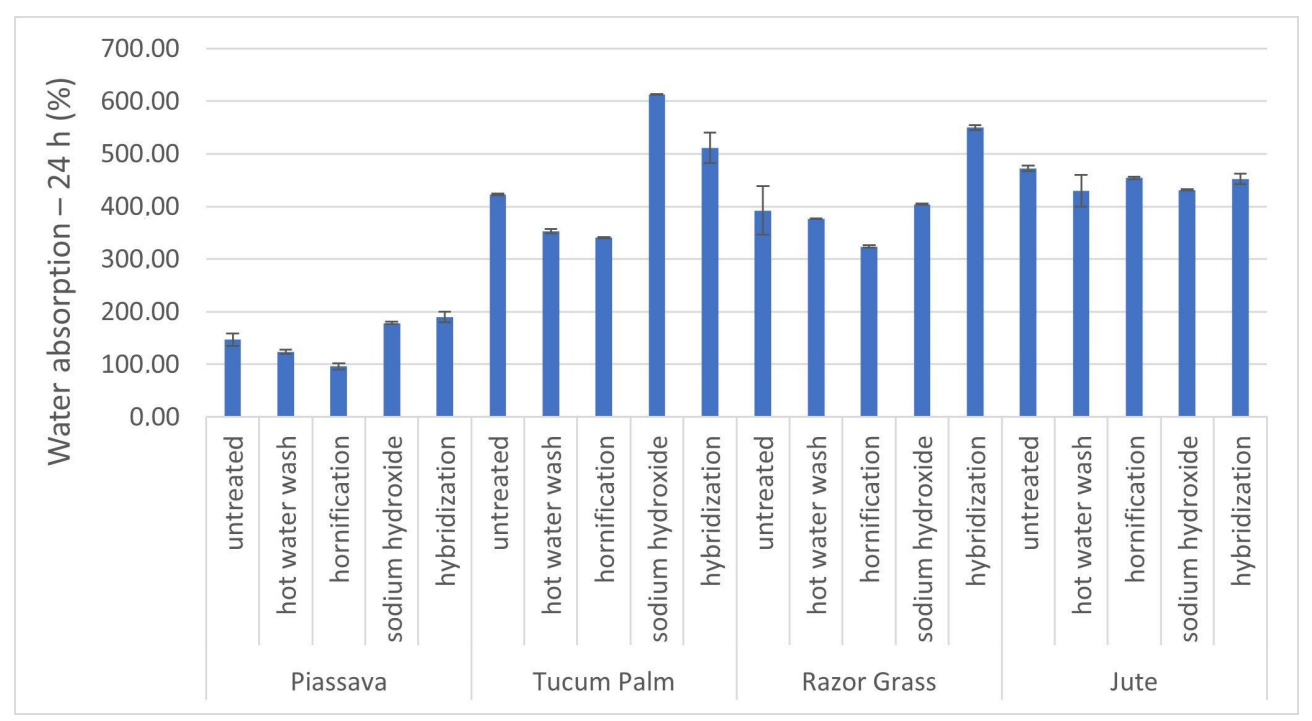

Figure 1. Untreated and treated fibers water absorption.

treatment results in lower water absorption due to changes in the fiber structures, which became more rigid and stiff ${ }^{3,9}$.

$\mathrm{NaOH}$ and hybridization treatments increased water absorption results for piassava, tucum and razor grass fibers. As a hypothesis, the removal of surface components with alkali that allowed such fibers absorb an even greater volume of water, due to exposure to $\mathrm{OH}$ groups belonging to cellulose (due to $\mathrm{NaOH}$ and hybridization treatments), making the fibers treated more hydrophilic, mainly with the removal of soluble substances that can lead to an increase in their mechanical strength, as it promotes the removal of the lignin (lower water absorption) and the increase in the amorphous cellulose portion (higher absorption of water) ${ }^{17,18}$

The $\mathrm{NaOH}$ treatment showed the highest absorption in the first 5 minutes, for piassava and tucum fibers. The hybridization showed greater absorption in 5 minutes for the jute and razor grass fibers.

Cellulose, hemicellulose and pectins are considered hydroxy group 1; they are generally hydrophilic and strong polar sources. The $\mathrm{NaOH}$ treatment increases the "polar" number of fibers. The superficial functionalities increased the amount of water absorbed in the fibers, probably due to the removal of substances such as gums and waxes from natural fibers. The increase of water absorption can also be explained by the changes in the surface quality of the fibers that after alkalis treatment became cleaner and with the possibility of formation of extra hydroxyl groups.

There is an increase in the hydrophilicity of the fibers, through the removal of hydrophobic substances that cover the fiber and by the formation of a rough fiber surface, and by the increasing of surface area ${ }^{19}$.

The hybridization treatment with the fibers bleaching with the use of hydrogen peroxide. The Bleaching makes the fibers more uniform, due to the removal of some extracellular materials; the degree of crystallinity increases (observed in tucum, razor grass and jute fibers) and the fibers acquire a whiter color. Water absorption is increased due to the removal of hydrophobic substances exposing hydrophilic sites, in addition the fibers lose some weight and become thinner ${ }^{20}$.

The maximum water absorption that the fibers of jute and razor grass presented are close to the cellulose fibers reported by Silva ${ }^{21}$ which resulted in absorption maximum of $643 \%$, both have the highest values of holocellulose contents. Palm fibers showed water absorption above $400 \%$ as observed by Benmansour et al. ${ }^{22}$.

According to Fidelis ${ }^{23}$ the water absorption capacity of the fibers is intricately linked to the amount of cellulose and hemicellulose present in the fibers, such a statement is consistent with the results obtained in the fibers chemical characterization, where the highest amounts of holocellulose and alpha-cellulose are present in the fibers that presented the highest absorption, respectively razor grass and jute fibers.

The untreated piassava fiber had an average water absorption of $147 \%$ and it was the lowest result. The water absorption presented by piassava fiber corroborates with the results presented by Savastano ${ }^{24}$ whose maximum measured absorption was $108 \%$.

The result of the absorption of untreated piassava fiber being equal to $147 \%$ was already the expected, since it is the fiber that presented an average value of lignin equal to $45.68 \%$ and lignin is the component that presents the lowest water absorption, among cellulose and hemicellulose.

\subsection{Crystallinity Index}

The XDR patterns of vegetal fibers are shown in Figure 2a, b, c, d. The piassava fiber with hot water treatment and hornification showed the highest crystalline peaks in the 002 plane, with respectively 1973 and 2087 intensities, in addition to more accentuated amorphous portion than the other treatments Figure 2a.

The hybridization treatment of tucum fibers presented the highest crystalline peak, with an intensity of 3316 . The tucum fiber crystallinity index was $11.51 \%$ higher than the untreated fiber, for this fiber the hornification treatment presented the second highest CI $(\%)=61.95 \%$. 

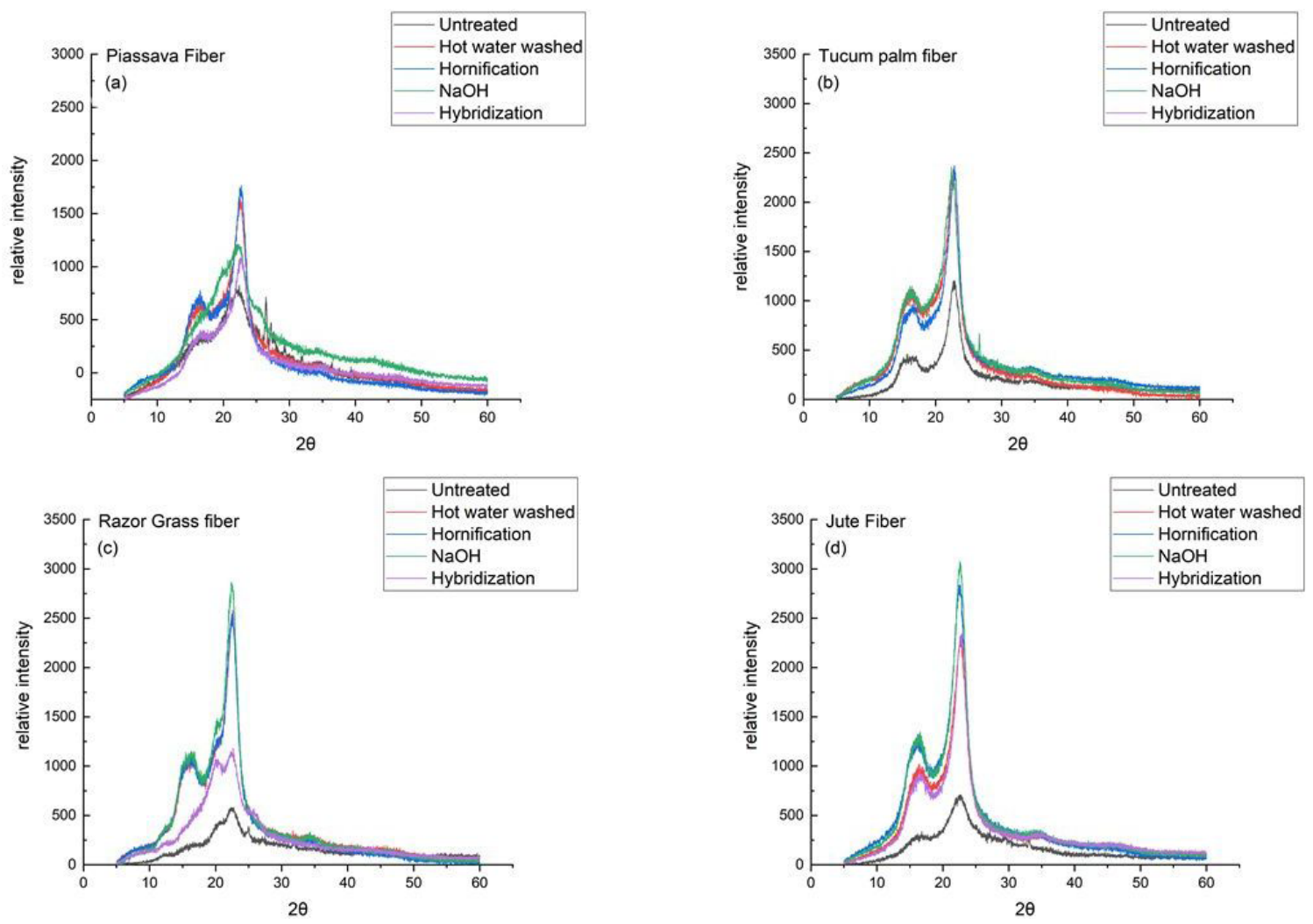

Figure 2. The XDR patterns of vegetal fibers: (a) piassava, (b) tucum palm, (c) razor grass and (d) Jute fibers.

The $\mathrm{NaOH}$, hornification and hot water treatments presented amorphous and crystalline peaks remarkably close to each other, as illustrated in the graph in Figure $2 \mathrm{~b}$. For the razor grass fibers, the XRD patterns showed in Figure 2c illustrate that the treatments, $\mathrm{NaOH}$, hornification and hot water obtained results more than twice of the crystalline peak (002 plane) in relation to the fiber without any treatment, however, the $\mathrm{CI} \%$ results are practically the same (60.23\% - no treatment) and (59.04\% - hybridization treatment), and the alkaline treatment $(57.61 \%-\mathrm{NaOH})$ and (57.23\% - Hot water).

The same result was observed for the jute fiber, where the crystallinity indexes did not show much difference (57.53\% - NaOH treatment) and (57\% - Hot water treatment). However, the values obtained are higher than those reported by Razera ${ }^{25}$ in which the treatments applied in jute fibers with $\mathrm{NaOH}(5 \%$ and $10 \%)$ presented $\mathrm{CI}(\%)$ respectively of (46\% and $48 \%$ ) which may be due to fiber variability. The chemical treatment $(\mathrm{NaOH})$ presented the second highest $\mathrm{CI}=57.53 \%$. The hybridization treatment resulted in the highest index of crystallinity.

The treatments implemented removed part of the amorphous material from the fibers, providing greater packing of cellulosic chains. Thus, it can be said that the treated fibers will have a better interaction with the cement matrix. The fibers that received alkaline treatment $(\mathrm{NaOH})$ and hybridization presented an increase in the amorphous peak at $2 \theta$ (between $14^{\circ}$ and $\left.16^{\circ}\right) 101$ and 021 planes, respectively, corroborating the results by Ouajai and Shanks ${ }^{26}$ who treated hemp fibers at concentrations of $3 \%, 5 \%, 8 \%, 10 \%, 12 \%, 15 \%$ and $20 \%$ of $(\mathrm{NaOH})$ and observed that the increase in the amorphous peak of the fibers, increased as the concentration of the alkaline solution increased. For all treatments performed on the jute fibers, the amorphous and crystalline peaks are well defined, as shown in Figure 2d.

Table 3 presents the fiber crystallinity index results and intensities of crystalline and amorphous peaks and their respective $2 \theta$ angles. It can be observed the effectiveness of hot water, $\mathrm{NaOH}$ and hornification treatments for piassava fibers, these treatments increased, respectively, 30\%, 25.11\% and $20.31 \%$ the crystallinity indexes of this fiber.

\subsection{Fibers direct tensile strength}

The graphics of Figure 3 show the results of direct tensile strength of the fibers without and with treatment. The highest tensile strength results (105.98 MPa) and modulus of elasticity (1.19 GPa) for Amazon Piassava fibers treated by NAOH solution are equivalent to the Northeast species (104 MPa and $2.19 \mathrm{GPa}$ ) obtained from the study of D'Almeida et al. ${ }^{27}$,

However, the highest crystallinity index of piassava fiber was through application of hot water treatment, corroborating authors and Martin et al. ${ }^{28}$, that state that not only the crystallinity of the fiber, but it also serves as a unique parameter to establish the mechanical performance of the fibers, other parameters such as angle and orientation of microfibrils, the number of cellulose crystals that make up the fiber, the length and width of the unit cells, also, exert influence on the mentioned performance. The increased fiber 


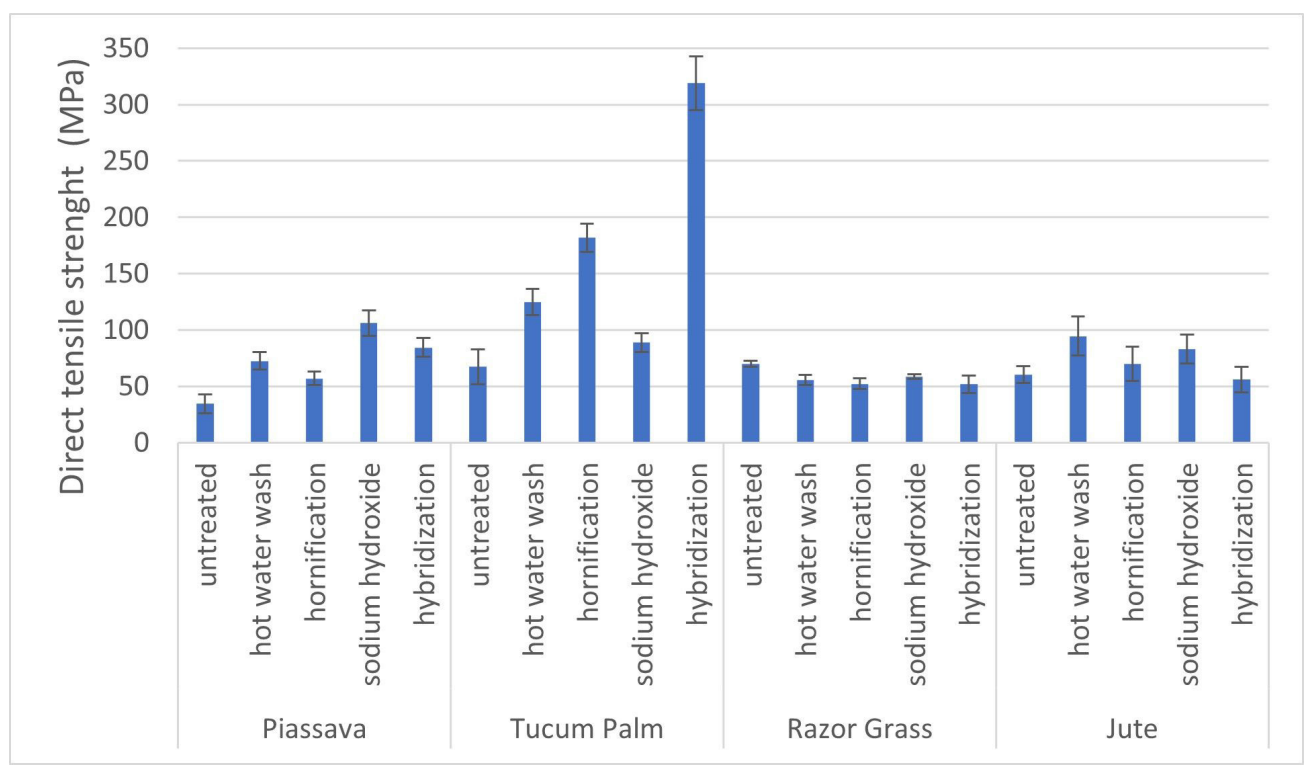

Figure 3. Direct Tensile strength of untreated and treated fibers.

Table 3. Relative intensities, $2 \theta$ angles of crystalline and amorphous peaks and crystallinity index C.I $(\%)$ results of untread and treated fibers.

\begin{tabular}{|c|c|c|c|c|c|c|}
\hline Fiber & Treatment & $\mathrm{I}_{(002)}$ & $2 \theta_{(002)}$ & $\mathrm{I}_{(\mathrm{am})}$ & $2 \theta_{(\mathrm{am})}$ & Crystallinity Index - C.I(\%) \\
\hline \multirow{5}{*}{ Piassava } & untreated & 1180 & $22.42^{\circ}$ & 710 & $15.98^{\circ}$ & 39.83 \\
\hline & hot water wash & 1973 & $22.50^{\circ}$ & 951 & $15.92^{\circ}$ & 51.80 \\
\hline & hornification & 2087 & $22.72^{\circ}$ & 1087 & $15.94^{\circ}$ & 47.92 \\
\hline & sodium hydroxide & 1469 & $22.18^{\circ}$ & 737 & $15.98^{\circ}$ & 49.83 \\
\hline & hybridization & 1350 & $22.78^{\circ}$ & 743 & $15.94^{\circ}$ & 44.96 \\
\hline \multirow{5}{*}{ Tucum Palm } & untreated & 1240 & $22.80^{\circ}$ & 498 & $15.74^{\circ}$ & 59.84 \\
\hline & hot water wash & 2457 & $22.66^{\circ}$ & 1208 & $15.74^{\circ}$ & 50.83 \\
\hline & hornification & 2402 & $22.84^{\circ}$ & 914 & $15.92^{\circ}$ & 61.95 \\
\hline & sodium hydroxide & 2450 & $22.38^{\circ}$ & 1211 & $15.88^{\circ}$ & 50.57 \\
\hline & hybridization & 3316 & $22.78^{\circ}$ & 1103 & $15.72^{\circ}$ & 66.73 \\
\hline \multirow{5}{*}{ Razor Grass } & untreated & 611 & $22.34^{\circ}$ & 243 & $15.70^{\circ}$ & 60.23 \\
\hline & hot water wash & 2656 & $22.64^{\circ}$ & 1136 & $15.78^{\circ}$ & 57.23 \\
\hline & hornification & 2708 & $22.62^{\circ}$ & 1213 & $15.96^{\circ}$ & 55.21 \\
\hline & sodium hydroxide & 2998 & $22.42^{\circ}$ & 1271 & $15.48^{\circ}$ & 57.61 \\
\hline & hybridization & 1245 & $22.66^{\circ}$ & 510 & $15.90^{\circ}$ & 59.04 \\
\hline \multirow{5}{*}{ Jute } & untreated & 761 & $22.60^{\circ}$ & 386 & $15.86^{\circ}$ & 49.28 \\
\hline & hot water wash & 2343 & $22.62^{\circ}$ & 1007 & $16.42^{\circ}$ & 57.00 \\
\hline & hornification & 2930 & $22.62^{\circ}$ & 1351 & $15.76^{\circ}$ & 53.89 \\
\hline & sodium hydroxide & 3138 & $22.58^{\circ}$ & 1333 & $15.88^{\circ}$ & 57.53 \\
\hline & hybridization & 2353 & $22.90^{\circ}$ & 899 & $15.90^{\circ}$ & 61.79 \\
\hline
\end{tabular}

tensile strength may not always represent an increase in its index of crystallinity.

The untreated piassava fiber showed straining between 6 and $10 \mathrm{~mm}$ of extension, this result is associated with the amount of lignin present in piassava fiber (45.68\%), since this component is a hardener and a chemical adhesive acting within and between fibers, therefore, according to Razera ${ }^{25}$ and Yan et al. ${ }^{29}$, this is chemical element is responsible for the great rigidity given to the piassava fiber.

The tucum fiber, with hybridization treatment, obtained direct tensile strength results superior to sisal, cotton, and coconut fibers, with a tensile strength of $318.81 \mathrm{MPa}$, result remarkably close to the strength of jute fiber (320 MPa), but with elasticity modulus (4.03 GPa) less than (12 GPa) than those reported by Yan et al. ${ }^{29}$ and Satyanarayna et al. ${ }^{30}$

It is noteworthy that the tucum fiber with the same treatment (hybridization) presented the highest crystallinity index $(66.73 \%)$ In addition, the tucum fiber presented direct tensile strength and modulus of elasticity higher than polypropylene (PP) fibers reported by Savastano et al. ${ }^{24}$ and Torgal and Jalali ${ }^{31}$.

The untreated razor grass fiber showed the same direct strength results as the fiber from date palm fibers (69.71 MPa) 
from the study by Torgal and Jalali ${ }^{31}$. However, with a smaller modulus of elasticity $0.6 \mathrm{MPa}$.

Therefore, treatments did not improve the mechanical property of razor grass fibers. The direct tensile results of treated fibers were inferior to those of the untreated ones; however, the results do not differ from each other statistically.

This result is linked to the amount of alpha-cellulose present in the untreated razor grass fibers $(86.85 \%)$ corroborating Fidelis ${ }^{23}$ statement that how much the greater the amount of cellulose found in the fibers, the greater is the mechanical tensile strength of it.

The jute fiber used in this work (cord), by hot water treatment resulted in a strength of $94.38 \mathrm{MPa}$ and a modulus of elasticity equal to $2.11 \mathrm{GPa}$, those results are close from Fidelis $^{23}$ (88 $\mathrm{MPa}$ and 2.27 GPa).

\subsection{Compressive test}

Figure $4 \mathrm{a}, \mathrm{b}, \mathrm{c}, \mathrm{d}$ shows the results of the compressive strength of mortars with treated and untreated fibers, with two types of cures: Cure with water and Cure with $\mathrm{CO}_{2}$ in an autoclave. The compressive strength of the reference sample without fibers, which was cured in autoclave with $\mathrm{CO}_{2}$, it was lower than that of the water cured sample.

This fact is due to the change in cement hydration chemistry. According to Wongkeo et al. ${ }^{32}$ and Yazic1 et al. ${ }^{33}$ the amount of $\mathrm{SiO}_{2}$ present in binding materials should be sufficient for the conversion of C-S-H to tobermorite $\left(\mathrm{C}_{5} \mathrm{~S}_{6} \mathrm{H}_{5}\right)$. The $\mathrm{CaO} / \mathrm{SiO}_{2}$ ratio must be between 0.88 and 1.36 and the temperature must be above $100{ }^{\circ} \mathrm{C}$, to be suitable for the formation of tobermorite.

In the present study, the amount of metakaolin (43.90\%) and fly ash (61.18\%), together with the autoclaved chamber temperature (below $100^{\circ} \mathrm{C}$ ) and pressure $(0.05 \mathrm{MPa})$, were not sufficient for this conversion and was one of the causes of reduced compressive strength of autoclaved samples.

According to Salem et al. ${ }^{34}$ the decrease in the compressive strength of composites can be linked to the increase in the air content incorporated in the composites, resulting the incorporation of vegetable fibers.

This fact corroborates the results observed for the composites. According to Kammoun and Trabelsi ${ }^{35}$ the decrease in compressive strength to vegetable fibers from a cementitious matrix may be related to low mechanical
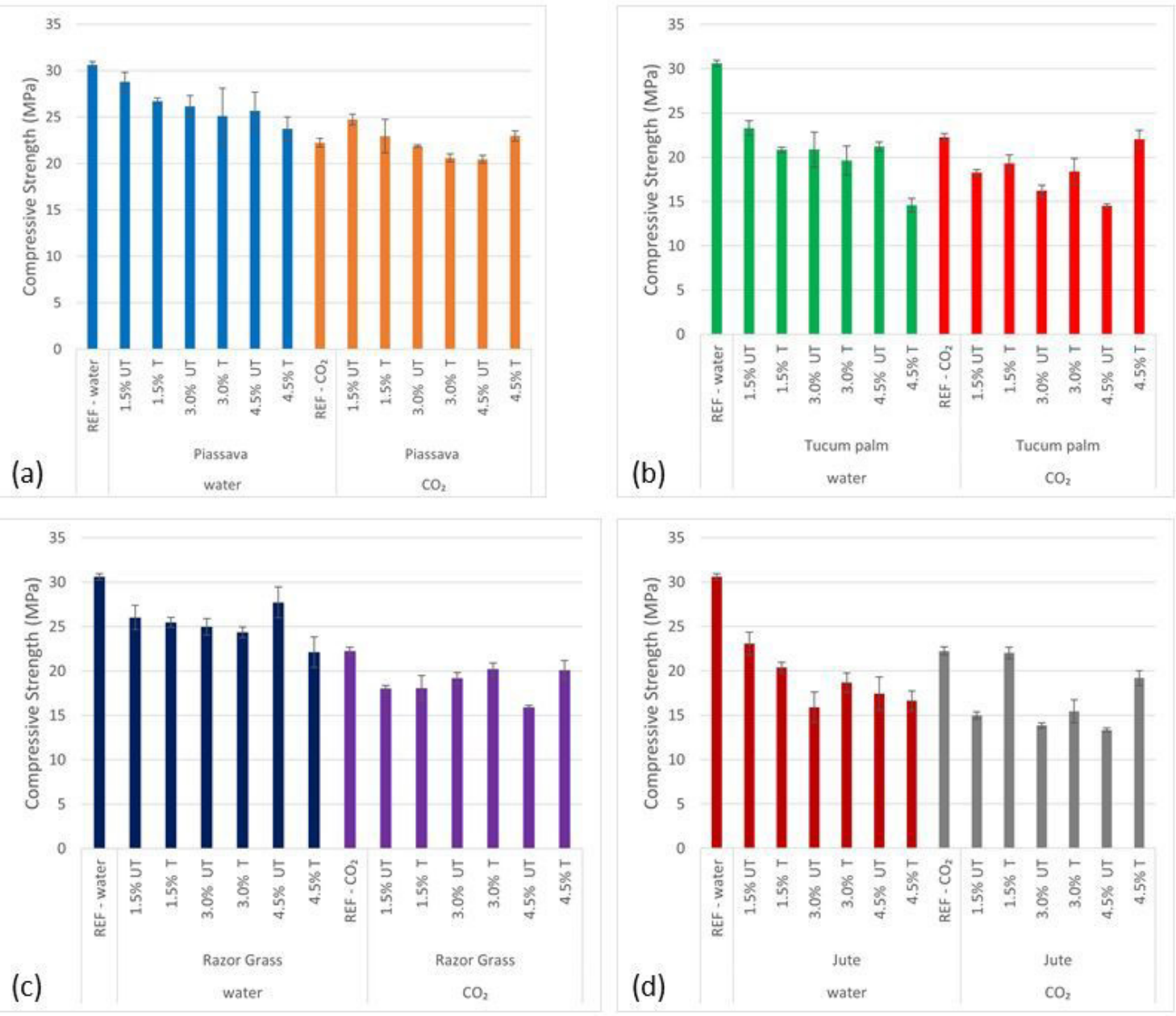

Figure 4. Compressive Strength samples: (a) piassava, (b) tucum palm, (c) razor grass and (d) Jute fibers at 28 days - obtained with samples cured with water and $\mathrm{CO}_{2}$. 
strength of inclusions, to the increase in porosity in the matrix due to the entry of air or lower adhesion of fiber/matrix.

In this study, the internal structure of the fibers (with the separation into microfibrils) due to the hybridization treatment, theoretically allowed good fiber/matrix adhesion. The slight increase in the strength of mortars with $4.5 \%$ of tucum fibers (Figure $4 \mathrm{~b}$ ) treated by hybridization, and jute fibers treated with $\mathrm{NaOH}$ solution (Figure 4d) can be attributed by the hydrophilicity presented by these fibers, and by the removal of substances hydrophobic, combined with the increased roughness of their surfaces.

The utilization of new technology, such as nanotechnology, may promote and increase mortars compressive strength. According to Kirgiz ${ }^{36}$ nanographite $(\mathrm{nG})$ particles consume the $\mathrm{Ca}(\mathrm{OH}) 2$ content of fly ashes binders. Nanographite perhaps can protect vegetable fibers in cement-reinforced mortars, since it promotes the reduction of the $\mathrm{Ca}(\mathrm{OH}) 2$ content.

\subsection{Flexural test}

Figure 5a, b, c, d shows the results of flexural strength of mortars with treated and untreated fibers, with two types of cures: Cure with water and Cure with $\mathrm{CO}_{2}$ in an autoclave.
The flexural strength of treated autoclaved fiber samples was lower than those samples cured in water. However, for samples with tucum palm (5.73 $\mathrm{MPa})$ and razor grass (6.19 $\mathrm{MPa}$ ) fibers, the results were slightly higher than the samples cured in water, respectively (4.64 $\mathrm{MPa}$ and 6.07 $\mathrm{MPa}$ ) Figures $5 \mathrm{~b}$ and $5 \mathrm{c}$.

These results suggested that the (hybridization and hornification) treatments promoted the best compatibility of connection between the fiber and matrix, along with the autoclave cure procedure. The alkaline hybridization treatment led to improved mechanical performance of samples with tucum palm fibers, since it reorganized the cellulose chains and divided the fiber into many more fibrils, which in turn raised the mechanical property of the direct tensile strength of the fiber from 67.2 MPa to $318.81 \mathrm{MPa}$ and increased the CI \% crystallinity index from $59.84 \%$ to $66.73 \%$.

The razor grass hornification treatment decreased the water absorption of the fibers, and consequently, the mixture had more free water to moisturize the pulp ${ }^{16}$. The greater number of fibers $(4.5 \%)$ resulted in the increase of fiber/ matrix adhesion. This led to an increase in flexural strength
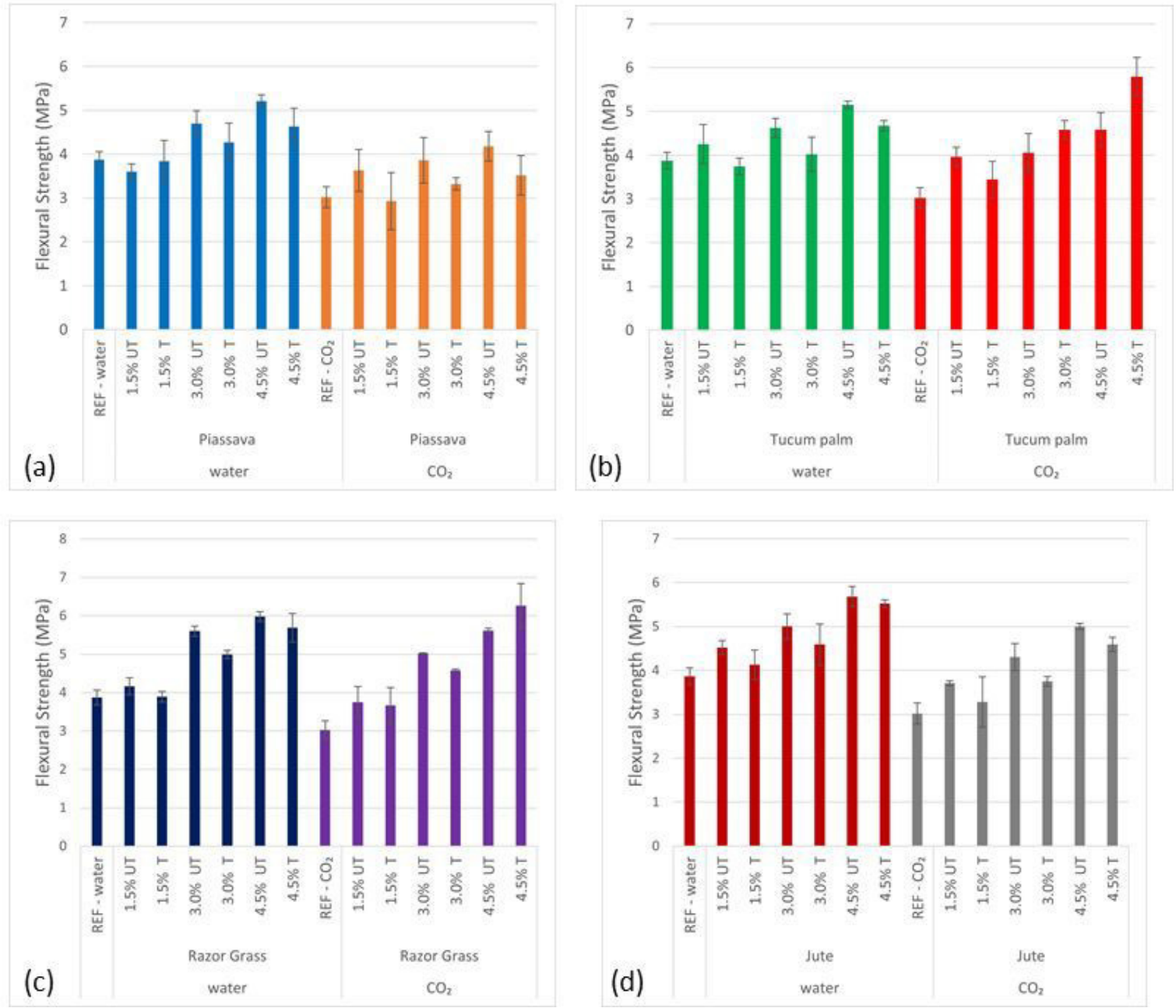

Figure 5. Flexural Strength samples: (a) piassava, (b) tucum palm, (c) razor grass and (d) Jute fibers at 28 days - obtained with samples cured with water and $\mathrm{CO}_{2}$. 
of $19.20 \%$ for treated mortars cured in the autoclave with inflated $\mathrm{CO}_{2}{ }^{37}$.

\subsection{Water absorption of mortars}

Figure 6 shows the results of capillary absorption of samples with untreated vegetable fibers. Samples with untreated vegetable fibers show higher values than the reference mortar, in the same exposure period, when adding a greater number of fibers (such as $4.5 \%$ ), the absorption increases due to hydrophilic characteristics of the fibers.

Mortars with jute fibers $(1.5 \% ; 3.0 \% ; 4.5 \%)$ showed capillary absorption equal to $7.31 \% ; 24.39 \%$ and $29.27 \%$ respectively higher than the mortar (REF), this fact can be explained due to the increase in the percentages of fibers and by the amount of hemicellulose that the untreated jute fiber presented (19.11\%) and the mortars with fibers from
Razor grass ( $8.41 \%$ of hemicellulose). In addition, the fibers can create larger interconnected pores, increasing the water permeability.

On the other hand, for fiber samples not treated with $\mathrm{CO}_{2}$ curing, it is observed the decrease in absorption in relation to the reference sample. This fact is due to the addition of natural fibers in cementitious matrices with good densification. According to Azevedo et al. ${ }^{37}$ the use of short fibers leads to disruption of interconnected internal pores. The reduced length of the fibers breaks the interconnections and reduce capillary water absorption.

Figure 7 shows the results of capillary absorption of mortars with treated fibers. For samples cured in water, the capillary absorption of tucum palm and jute samples were higher than the reference samples, due to the treatments in the fiber of jute $(\mathrm{NaOH}$ solution) and in tucum fiber

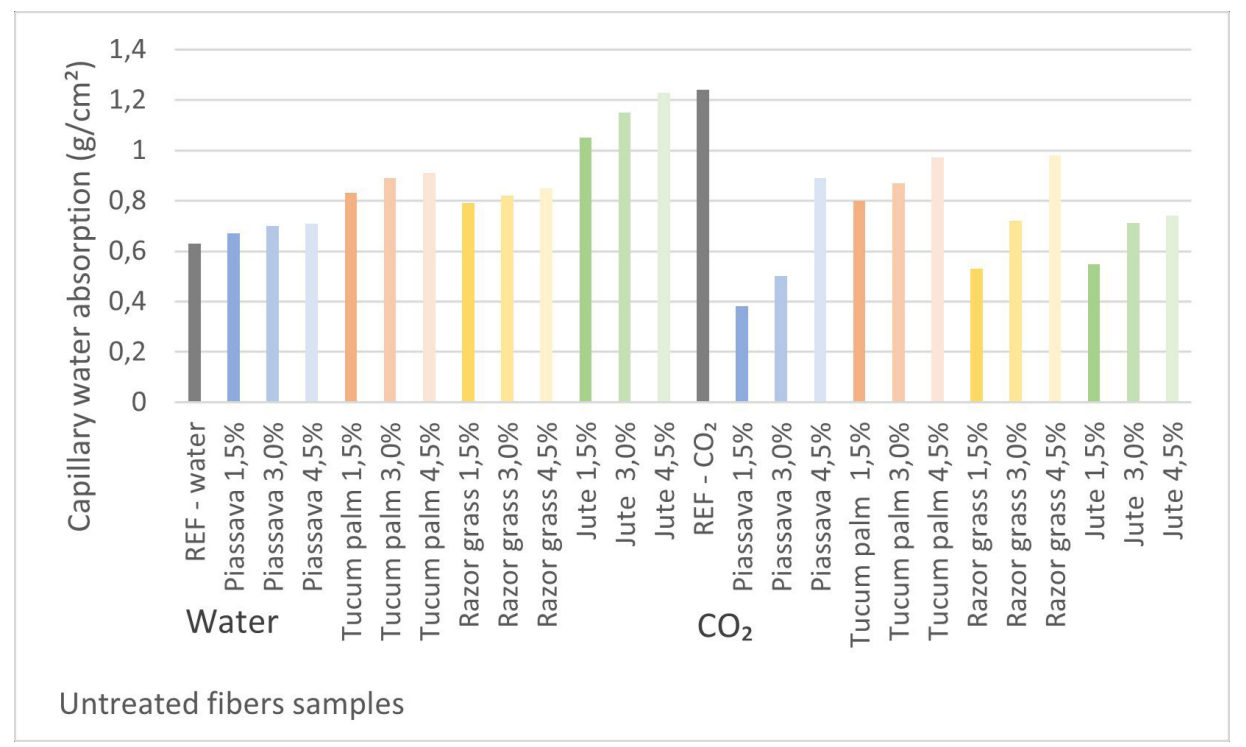

Figure 6. Capillary water absorption - Untreated fibers samples at 28 days - obtained with samples cured with water and $\mathrm{CO}_{2}$.

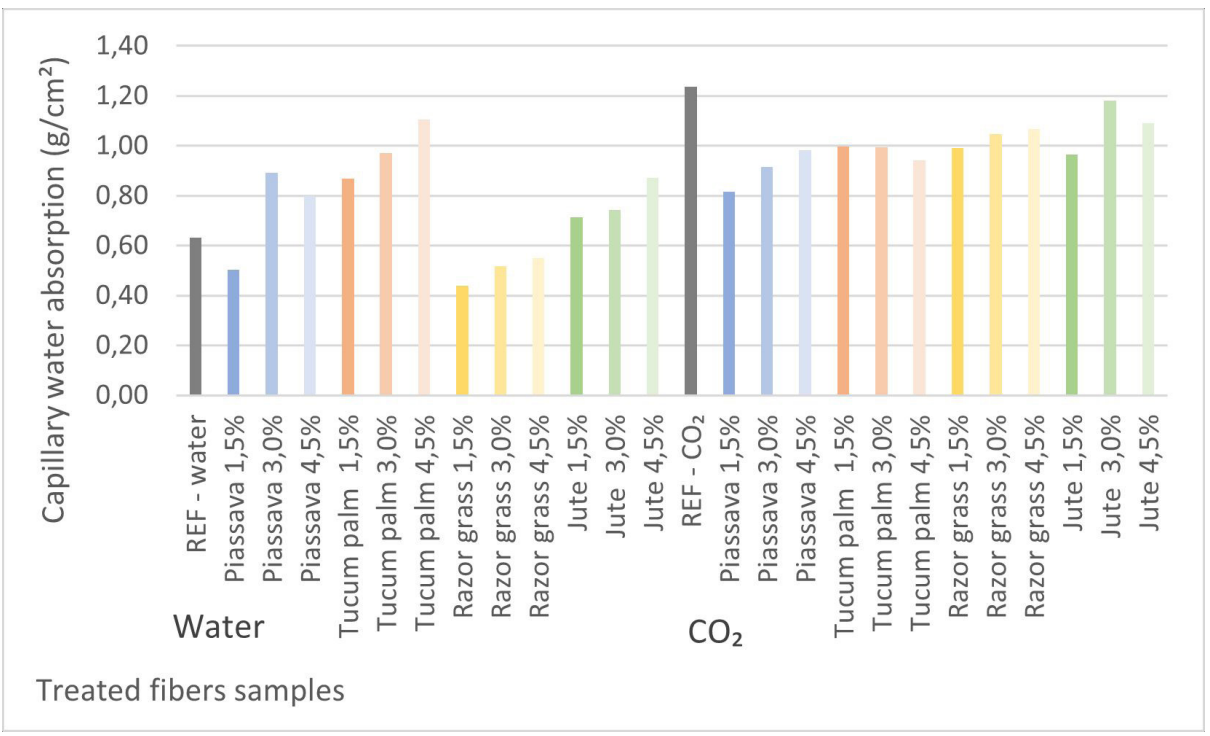

Figure 7. Capillary water absorption - Treated fibers samples at 28 days - obtained with samples cured with water and $\mathrm{CO}_{2}$. 
(hybridization) that exposed the $\mathrm{OH}$ groups of cellulose, already mentioned above.

This phenomenon intensifies with the increase of fiber percentages (from $1.5 \%$ to $4.5 \%$ ). For samples with razor grass fibers the capillary absorption was lower due to the hornification cycles that decreased the absorption capacity of the fibers.

For samples with treated fibers, capillary absorption was lower than reference sample (without fibers) due to two factors: The fibers interrupted the interconnection of the capillary internal pores and the type of cure (autoclave with $\mathrm{CO}_{2}$ ).

According to Soroushian et al. ${ }^{38} \mathrm{CO}_{2}$ in contact with water forms carbonic acid $\left(\mathrm{H}_{2} \mathrm{CO}_{3}\right)$ which it reacts with portlandite $(\mathrm{CH})$ consuming it and transforming it into calcium carbonate $\left(\mathrm{CaCO}_{3}\right)$. $\mathrm{CaCO}_{3}$ fills the voids in the matrix and fibers and causes the buffering effect that densify the composite matrix ${ }^{39}$.

\section{Conclusion}

The aim of the study was to examine the feasibility of using 4 natural fibers, from the Amazon forest (piassava, tucum palm, razor grass and jute) as an alternative to reinforcement in composite cement materials through the proposal of alternative treatments applied to natural fibers (hot water washing, hornification cycles, application of sodium hydroxide solution and hybridization treatment) combined with incorporation of supplementary cementitious materials (MCS) for mortars and types of alternative cures (cure in an autoclave of water and $\mathrm{CO}_{2}$ ).

From this study, it can be deduced that the crystallinity index depends on the concentration alkalis and the compressive strength of mortars. The highest fiber tensile strength result was equal to $318.81 \mathrm{MPa}$, evidenced by the highest crystallinity index found of $66.73 \%$ for the tucum palm fibers. The results of comparing multiple direct tensile strength averages for the tucum palm fibers showed that the hybridization treatment differs from the others, being, therefore, the most effective.

After the hybridization treatment, the tucum fibers showed some reduction in their less resistant chemical compounds and it was enough to increase the mechanical behavior, also to increase the crystallinity of the cellulose, changing its chemical bonds, especially the hidroxyl groups that increased the water absorption capacity of fiber, explained by the change in the crystallinity of the cellulose with reduction amorphous material of fibers.

Autoclave curing with $\mathrm{CO}_{2}$ increased the compressive strength of tucum palm and jute composites with $4.5 \%$ fiber. The above statement can be confirmed by the observed reduction in water absorption by capillarity of samples with treated fibers of jute and tucum palm $(4.5 \%)$, composites presented, respectively, $0.94 \mathrm{~g} / \mathrm{cm}^{2}$ and $1.09 \mathrm{~g} / \mathrm{cm}^{2}$, reductions of $24.19 \%$ and $12.10 \%$ compared to composites (REF) without fibers.

The presence of fibers increases the porosity and total absorption of composites, such as it can also reduce the interconnection between these pores, including reducing microcracks in the matrix and capillary absorption.

The failure mechanism of composites is complex, involving flaws and cracks in the cementitious matrix. The fiber structure after treatments with superficial grooves, contributed to minimal fiber shedding, and improved composite performance during the mechanical tests, after bending strength limits, the composites continued to support loads without breaking suddenly, and with high deformation, especially for composites with piassava fibers.

The flexural strength of cementitious composites reinforced with $4.5 \%$ fiber tucum and razor grass submitted to curing in an autoclave with $\mathrm{CO}_{2}$ was, respectively, $49.61 \%$ and $61.75 \%$ higher that the reference (without fibers) in water cure, preserved their ductility and reinforcing capabilities, reaching flexural strengths close to or higher than those with curing in water (a less aggressive curing method).

Autoclave curing with $\mathrm{CO}_{2}$ used in this study may be a viable alternative for the manufacture of composites with vegetable fibers for the most remote regions (such as the Amazon region) as well as treatments applied to the fibers, which in addition to being simple, cheap, easy to carry out and manage. Therefore, it is suitable for the purpose of manufacturing hollow blocks for masonry, according to the NBR $6136^{40}$ where the minimum compressive strength is $8.00 \mathrm{MPa}$.

The results from this paper in terms of compressive and flexural strength, fibers direct tensile strength, fibers water absorption and surface fibers treatments may encourage producing similar new mixes for non-structural applications such as paving blocks and tiles, also to structural reinforced concrete members.

These would let to study the development of more resistant and durable building materials. Investigations are needed to reduce cement content by using other additions, like fillers to produce mortars which the science of the new material behavior can be investigated and explored.

\section{Acknowledgements}

The authors gratefully acknowledge the National Council for Scientific and Technological Development (CNPq), CAPES, for financial support of this work.

\section{References}

1. Leshmi MS, Vishudas S, Anil KR. Lignocellulosic materials as reinforcement and replacement for binders in masonry mortar. Constr Build Mater. 2021;282:122607.

2. Tomassetti L, Giuseppe DD, Zoboli A, Paolini V, Torre M, Paris E, et al. Emission of fibres and atmospheric pollutants from the thermal treatment of asbestos containing waste (ACW). J Clean Prod. 2020;268:122179.

3. Lertwattanaruk P, Suntijitto A. Properties of natural fiber cement materials containing coconut coir and oil palm fibers for residential building applications. Constr Build Mater. 2015;94:664-9.

4. Satyanarayana KG, Guimarães JL, Wypych F. Studies on lignocellulosic fibers of Brazil. Part I: source, production, morphology, properties and applications. Compos, Part AAppl Sci Manuf. 2007;38:1694-709.

5. Savastano H, Warden PG, Coutts RSP. Microstructure and mechanical properties of waste fibre-cement composites. Cement Concr Compos. 2005;27:583-92.

6. Tian H, Zhang YX, Yang C, Ding Y. Recent advances in experimental studies of the mechanical behaviour of natural 
fibre-reinforced cementitious composites. Struct Concr. 2016;17(4):564-75.

7. ABNT: Associação Brasileira de Normas Técnicas. NBR 16697: Cimento Portland - Requisitos. Rio de Janeiro: ABNT; 2018.

8. Yan L, Kasal B, Huang L. A review of recent research on the use of cellulosic fibres, their fibre fabric reinforced cementitious, geo-polymer and polymer composites in civil engineering. Compos, Part B Eng. 2016;92:94-132.

9. Asasutjarit C, Charoenvai S, Hirunlabh J, Khedari J. Materials and mechanical properties of pretreated coir-based green composites. Compos, Part B Eng. 2009;40:633-7.

10. Ferreira SR, Silva FA, Lima PRL, Toledo Filho RD. Effect of hornification on the structure, tensile behavior and fiber matrix bond of sisal, jute and curauá fiber cement based composite systems. Constr Build Mater. 2017;139:551-61.

11. Segal L, Creely JJ, Martin AE, Conrad CM. An empirical method for estimating the degree of crystallinity of native cellulose using the x-ray diffractometer. Textile Research Journal. 1959;29(10):786-94.

12. ASTM: ASTM International. ASTM C1557: Standard Test Method for Tensile Strength and Young's Modulus of Fibers. West Conshohocken: ASTM; 2020.

13. ABNT: Associação Brasileira de Normas Técnicas. NBR 13279: Argamassa para assentamento e revestimento de paredes e tetos - Determinação da resistência à tração na flexão e à compressão. Rio de Janeiro: ABNT; 2005.

14. ABNT: Associação Brasileira de Normas Técnicas. NBR 9779: Argamassa e concreto endurecidos - Determinação da absorção de água por capilaridade. Rio de Janeiro: ABNT; 2012.

15. Ballesteros JEM, Santos SF, Mármol G, Savastano R, Fiorelli J. Evaluation of cellulosic pulps treated by hornification as reinforcement of cementitious composites. Constr Build Mater. 2015;100:83-90.

16. Claramunt J, Ardanuy M, García-Hortal JA, Tolêdo RD Fo. The hornification of vegetable fibers to improve the durability of cement mortar composites. Cement Concr Compos. 2011;33(5):586-95.

17. Dhanalakshmi D, Punyamurthy R, Bennehalli B, Chikkol Venkateshappa S. Effect of esterification on moisture absorption of single areca fiber. Int J Agric Sci. 2012;4:227-9.

18. Quiroga A, Marzocchi V, Rintoul I. Influence of wood treatments on mechanical properties of wood-cement composites and of Populus Euroamericana wood fibers. Compos, Part B Eng. 2016;84:25-32.

19. Bennehalli B, Sampathkumar D, Punyamurth R, Venkateshappa SC. Effect of Esterification on moisture absportion of single areca fiber. Int J Agric Sci. 2012;4:227-9.

20. Yilmaz ND. Agro-residual fibers as potential reinforcement elements for biocomposites. In Thakur, V.K., ed. Lignocellulosic polymer composites. Denizli, Turkey: Scrivener Publishing; 2014. pp. 231-70

21. Silva AC. Estudo da durabilidade de compósitos reforçados com fibras de celulose [dissertação]. São Paulo: Escola Politécnica, Universidade de São Paulo; 2002.

22. Benmansour N, Boudjemaa A, Gherabli A, Kareche A, Boudenne A. Thermal and mechanical performance of natural mortar reinforced with date palm fibers for use as insulating materials in building. Energy Build. 2014;81:98-104.

23. Fidelis MEA, Toledo RD Fo, de Andrade Silva F, Mobasher B, Müller S, Mechtcherine V. Interface characteristics of jute fiber systems in a cementitious matrix. Cement Concr Res. 2019; 116:252-65.

24. Savastano HJR, Agopyan V, Nolasco AM, Pimentel L. Plant fibre reinforced cement components for roofing. Constr Build Mater. 1999;13(8):433-8.

25. Razera IAT. Fibras lignocelulósicas como agente de reforço de compósitos de matriz fenólica e lignofenólica [tese]. São Carlos: Universidade de São Paulo; 2006.

26. Ouajai S, Shanks RA. Biocomposites of cellulose acetate butyrate with modified hemp cellulose fibres. Macromol Mater Eng. 2009;294(3):213-21

27. D'almeida JRM, Aquino RCMP, Monteiro SN. Tensile mechanical properties, morphological aspects and chemical characterization of piassava (Attalea funifera) fibers. Compos, Part A Appl Sci Manuf. 2006;37(9):1473-9.

28. Martin AR, Martins MA, Mattoso LHC, Silva ORRF. Caracterização química e estrutural de fibra de sisal da variedade Agave sisalana. Polímeros. 2009;19(1):40-6.

29. Yan L, Bohumil K, Huang LA. A review of recent research on the use of cellulosic fibres, their fibre fabric reinforced cementitious, geo-polymer and polymer composites in civil engineering. Compos, Part B Eng. 2016;92:94-132.

30. Satyanarayana KG, Guimarães JL, Wypych F. Studies on lignocellulosic fibers of Brazil. Part I: Source, production, morphology, properties and applications. Compos Part AAppl Sci Manuf. 2007;38(7):1694-709.

31. Torgal FP, Jalali S. Cementitious building materials reinforced with vegetable fibres: a review. Constr Build Mater. 2011;25:57581.

32. Wongkeo W, Thongsanitgarn $\mathrm{P}$, Chaipanich A. Compressive strength of binary and ternary blended cement mortars containing fly ash and silica fume under autoclaved curing. Adv Mat Res. 2012;343:316-21.

33. Yazıcı H, Yardımcı MY, Aydın S, Karabulut AŞ. Mechanical properties of reactive powder concrete containing mineral admixtures under different curing regimes. Constr Build Mater. 2009;23:1223-31.

34. Salem T, Fois M, Omikrine-metalssi O, Manuel R, Fen-chong T. Thermal and mechanical performances of cement-based mortars reinforced with vegetable synthetic sponge wastes and silica fume. Constr Build Mater. 2020;264:120213.

35. Kammoun Z, Trabelsi A. Development of lightweight concrete using prickly pear fibres. Constr Build Mater. 2019;210:269-77.

36. Kırgız MS. Green cement composite concept reinforced by graphite nano-engineered particle suspension for infrastructure renewal material. Compos, Part B Eng. 2018;154(12):423-9.

37. Azevedo ARG, Marvila MT, Tayeh BA, Cecchin D, Pereira AC, Monteiro SN. Technological performance of açaí natural fibre reinforced cement-based mortars. J Build Eng. 2021;33:101675.

38. Soroushian P, Won J-P, Hassan M. Durability characteristics of $\mathrm{CO}_{2}$-cured cellulose fiber reinforced cement composites. Constr Build Mater. 2012;34:44-53.

39. de Azevedo ARG, Marvila MT, Tayeh BA, Cecchin D, Pereira AC, Monteiro SN. Technological performance of açaí natural fibre reinforced cement-based mortars. J Build Eng. 2021;33:101675.

40. ABNT: Associação Brasileira de Normas Técnicas. NBR 6136: Blocos vazados de concreto simples para alvenaria - Requisitos. Rio de Janeiro: ABNT; 2016. 